\title{
Opioid-dependence Syndrome
}

\author{
Prabavathy Subramanian ${ }^{1}$, Jayasri Jayamoorthy ${ }^{2}$
}

\begin{abstract}
Opioids is a natural and synthetic painkillers derived from the poppy plant used for medication. Opioids, are called narcotics, a type of drug. The commonly used opioids are morphine, codeine, heroin, opium, oxymorphone, tramadol used as a strong prescription for relieving pain. Opioids dependence syndrome needs the compulsive and uncontrollable use of opioid drugs causing adverse consequences. Dependency occurs when the body adapts to the presence of the drug, causing withdrawal symptoms when drug use is reduced or discontinued. The prevalence of opiod use in India was found to be $0.7 \%$ of the general population and $22.3 \%$ were found to be dependent on opiods. The patient is presented with elated or euphoric state, intermittent nodding off, depression, drowsiness, lethargy even loss of consciousness. The co-occurring mental disorders include bipolar disorder, anxiety disorders, depressive disorders, schizophrenia, conduct disorder, personality disorder. The mainstay of treatment includes detoxification therapy and psychological therapy.

Keywords: Co-occurring mental disorders, Detoxification therapy, Opioids, Opioids dependence syndrome, Psychological therapy.

Pondicherry Journal of Nursing (2019): 10.5005/jp-journals-10084-12110
\end{abstract}

\section{INTRODUCTION}

Opioid is a natural and synthetic painkillers derived from the poppy plant used for medication. Opioids are called narcotics, a type of drug. ${ }^{2}$ Opiate addiction is in the form of misuse and chronic abuse of opioid pain relief medications, such as morphine, codeine, heroin, opium, oxymorphone and tramadol. Dependence and abuse of the prescription opioid drugs is a major health-related problem among adoloscents.

\section{Case Description}

A 19-years male was admitted with the complaints of agitation, irritability, anxiety, increased psychomotor activity, dry mouth, decreased sleep, decreased appetite, depression, body ache and burning pain in the abdomen for past 5 months, not listening to class, tremors on hands, someone trying to kill him, suspicious about mother and other relatives, inability to make decision, feeling of insecurity, threatened his mother and attempted to commit suicide for three times within a week for last 2 months. Due to peer group influence he had taken tab. tapentadol 250-300 mg/day to relieve from pain, later he got addicted to drug and frequency was increased 8-10 times a day for past 2 years. Patient developed co-occurring psychiatry disorder like BPAD with anxiety disorder. Patient had a previous history of same complaints and got treatment in private hospital. Patient has improved his condition after his treatment schedule.

\section{History Taking}

Due to peer group influence, use of tab. tapentadol 250$300 \mathrm{mg} /$ day to relieve from pain, later got addicted to drug and frequency was increased 8-10 times a day for past 2 years.

\section{Mental Physical Status and Examination}

The patient had increased psychomotor activity, delusion of persecution, euphoria hopelessness and suicidal thoughts, and in physical examination, the patient had drowsiness, slowed breathing (temp.: $36.8^{\circ} \mathrm{C}$, respiratory rate: 16 breath/minutes, pulse: 90 beats/minutes) and constipation.
1,2Department of Mental Health Nursing, Kasturba Gandhi Nursing College, Sri Balaji Vidyapeeth, Puducherry, India

Corresponding Author: Prabavathy Subramanian, Department of Mental Health Nursing, Kasturba Gandhi Nursing College, Sri Balaji Vidyapeeth, Puducherry, India, Phone: +91 9942936944, e-mail: prabavathy111@gmail.com

How to cite this article: Subramanian P, Jayamoorthy J. Opioiddependence Syndrome. Pon J Nurs 2019;12(1):13-14.

Source of support: Nil

Conflict of interest: None

\section{Investigation}

Sr. creatinine-0.92 mg/dL, Sr. urea-17 mg/dL, Sr. sodium$136 \mathrm{mEq} / \mathrm{dL}, \mathrm{Sr}$. postassium- $5.4 \mathrm{mEq} / \mathrm{dL}$ and $\mathrm{Sr}$. chloride$105 \mathrm{mEq} / \mathrm{dL}$.

\section{Impression}

Based on the ICD 10 classifications, the patient was diagnosed as F11 - mental and behavior disorder due to use of opioids.

\section{Treatment}

Patient received detoxification therapy tab. methadone 40-60 mg/day, oral, OD for a week and mood stabilizer like tab. sodium valporate $600 \mathrm{mg} \mathrm{BD}$ and tab. diazepam $50 \mathrm{mg}$ for a week and following the patient underwent 6 sessions of ECT, after several psychotherapy like individual therapy, group, family counseling and behavior therapy. The patient condition was improved and he learned adaptive behavior and showed improvement in the coping skill and decision making capacity. Nursing care plan was based on the priority needs and patient remained on monitoring of vital functions, direct observation in administration of medication, IV fluid therapy, proper nutrition and assisted in various therapies. On discharge patient and family were educated about drug compliances, availability of rehabilitation services in community and importance of follow-up.

\section{Follow-up}

- The patient got discharge after the 6th session of ECT.

o The Author(s). 2019 Open Access This article is distributed under the terms of the Creative Commons Attribution 4.0 International License (https://creativecommons. org/licenses/by-nc/4.0/), which permits unrestricted use, distribution, and non-commercial reproduction in any medium, provided you give appropriate credit to the original author(s) and the source, provide a link to the Creative Commons license, and indicate if changes were made. The Creative Commons Public Domain Dedication waiver (http://creativecommons.org/publicdomain/zero/1.0/) applies to the data made available in this article, unless otherwise stated. 
- The patient condition was improved physically, psychologically and how able to maintain day-to-day activities.

- Attending regular sessions of counseling, therapies and the plan of visit after 10 days.

\section{Discussion}

Opioid-dependence syndrome is defined as the compulsive and uncontrollable use of opioids causing group of physiological, behavioral and cognitive disturbances. ${ }^{1,3,9}$ The prevalence of opiod use in India was found to be $0.7 \%$ of the general population and $22.3 \%$ were found to be dependent on opiod. ${ }^{2,5}$ The biopsychosocial factors leading to opioid-dependence syndrome were genetic vulnerability, comorbid psychiatric disorder, curiosity, novelty seeking, low self esteem, peer pressure, modeling, ease of availability of drugs and intrafamilial conflicts. The clinical features of opioid-dependence syndrome includes physical symptoms such as elation, euphoria, drowsiness, confusion, pinpoint pupils, slowed breathing and psychological symptoms like addiction, memory problems, hallucinations, and delusions. ${ }^{6,8}$ The diagnoses were based on the ICD10 criteria, history taking, physical and mental status examination and blood investigation. The treatment includes pharmacological management with detoxification therapy by use of tab. methadone- $40-60 \mathrm{mg} / \mathrm{dL}$, tab. naloxone-12-16 mg/dL, and tab. clonidine-0.3-1.2 mg/day. Psychotherapies such cognitive behavioral therapy, interpersonal therapy, motivational enhancement therapy, self control strategies, narcotics anonymous and group and family therapy ${ }^{4}$ as meditation, spiritual counseling, motivational interviewing, nutrition therapy. The co-occurring psychiatry disorders like bipolar disorder, anxiety disorders, depressive disorders, schizophrenia, conduct disorders, antisocial personality disorder, borderline personality disorder due to use of opioids and drug-dependence complication such as parkinsonism, peripheral neuropathy, complication due to IV use of drug causing AIDS, skin infection, hepatitis and involvement in criminal activities. ${ }^{7,10}$

\section{Declaration of Patient Consent}

The authors certify that they have obtained all appropriate patient consent forms. In the form, the patient has given his consent for his images and other clinical information to be reported in the journal. The patient understand that his name and initial will not be published and due efforts will be made to conceal her identity, but anonymity cannot be guaranteed.

\section{References}

1. American Psychiatric Association. Diagnostic and Statistical Manual of Mental Disorders, 5th ed. Arlington, VA: American Psychiatric Association; 2013.

2. National Survey on Drug Use and Health: Detailed Tables. Substance Abuse and Mental Health Administration, Rockville, MD; 2016.

3. Sharma B, Bruner A, Barnett G, Fishman M. Opioid Use Disorders. Child Adolesc Psychiatr Clin N Am 2016 Jul;25(3):473-487. DOI: 10.1016/j.chc.2016.03.002.

4. Townsend MC. Psychiatric Mental Health Nursing, 5th ed. New Delhi: Jaypee Medical Publishers; 2007.

5. Videbeck SL. Psychiatric Mental Health Nursing, 3rd ed. Philadelphia: Lippincott Williams and Wilkins; 2006.

6. Stuart G. Principles and Practice of Psychiatric Nursing, 8th ed. Mosby Publication; 2004.

7. Ahuja N. A short Textbook of Psychiatry, 5th ed. New Delhi: Jaypee Brothers Publication; 2002.

8. Lalitha K. Textbook of Psychiatric Nursing, 1st ed. Bangalore; 2004.

9. Dole VP, Nyswander M, Kreek MJ. Narcotic blockade. Arch Intern Med 1996;118:304-309.

10. Videbeck SL. Psychiatric Mental Health Nursing, 3rd ed. Philadelphia: Lippincott Williams and Wilkins; 2006. 